\title{
Sharing Digital Photographs in the Home through Physical Mementos, Souvenirs, and Keepsakes
}

\author{
Michael Nunes, Saul Greenberg and Carman Neustaedter \\ Department of Computer Science, University of Calgary \\ Calgary, AB, CANADA T2N 1N4 \\ $+14032206087$ \\ nunes@cpsc.ucalgary.ca, saul.greenberg@ucalgary.ca, carman@cpsc.ucalgary.ca
}

\begin{abstract}
People now easily share digital photos outside the home via web publishing and gift-giving. Yet within the home, digital photos are hard to access and lack the physical affordances that make sharing easy and opportunistic. To promote in-home photo sharing, we designed Souvenirs, a system that lets people link digital photo sets to physical memorabilia. These mementos trigger memories and serve as social instruments; a person can enrich their storytelling by moving the physical memento close to their largeformat television screen, and the associated photos are immediately displayed. We implemented Souvenirs, and then reexamined our design premises through contextual interviews with 20 households. Families described their current practices of photo sharing and memento use, and also reacted to the Souvenirs design. Based on these interviews, we redesigned Souvenirs to better fit the real practices of photo and memento use in the home.
\end{abstract}

\section{Categories and Subject Descriptors}

H.5.2 [User Interfaces]: Graphical user interfaces (GUI), Input devices and strategies, Interaction styles, user-centered design.

\section{General Terms. Design, Human Factors.}

Keywords. Ubiquitous computing, digital photo management.

\section{INTRODUCTION}

The goal behind much of the current research in ubiquitous computing - especially in domestic computing - is to design computing technologies to fit in with existing routines and practices within the home [5]. In particular, researchers have found that household members regularly position information artifacts - paper calendars, school notices, handwritten notes, etc. - at particular locations within the home. These contextual locations strongly influence how people share, stay aware of, and interact with information in a timely manner [6][3].

In contrast, digital information is constrained to the traditional desktop computers found in many homes: its fixed location often in a home office or den - means that information on these computers rarely exploit the rich nuances of location. Yet information relevant to the household is increasingly becoming digital, replacing traditional physical forms such as: paper documents, letters, music and video collections, and photographs.

Perhaps because of this situation, most systems developed so far for managing domestic information tend to provide excellent affordances for viewing or exchanging content across distributed sites - between distant family members, relatives, friends and even strangers. The means include email, file transfers in instant messengers, web sites devoted to sharing, e.g., Flickr [13], peer to peer programs for music, and so on.

While such sharing of digital information is now easy over distance, sharing within the home environment between copresent people has become problematic. As mentioned, the desktop computer does not normally exploit locations, which means that there are fewer serendipitous opportunities for copresent people to socially engage over digital artifacts. As well, digital information is awkward to get: people have to $\log$ on, navigate to that information, and invoke the correct application to view it. The consequence is that co-present sharing typically happens only if there is a strong desire by all members, and only if the owner of that information is present to access and display it.

Within this context, our focus is the family photograph. The photo is an excellent example of a common domestic artifact that has evolved from a primarily physical to now mostly digital media in a very short amount of time. Photos have many properties that are interesting to domestic research [2][1][4]: home inhabitants take many of them; some spend a considerable amount of time sorting them into collections for display (e.g., photo albums); people personalize their homes with photos (e.g., framed photos); photos often become the focus of social activity (e.g., storytelling); and people often gift photos to one another. Yet digital photos inhibit some of these activities: "the technology of digital picture transmission, printing, file sharing, and display are sufficiently complex and time-consuming as to prevent many people from saving, retrieving, and sharing the pictures they cherish" [16].

So far, most HCI research on digital photography has improved how people manage, sort and manipulate their personal photo collections, and how they share photos over distance with others. There is also research in the storytelling that happens after photo sharing begins [4][19]. In contrast, our interest is situating digital photo collections within the home in a way that opportunistically and naturally triggers photo-sharing and storytelling in the faceto-face setting provided by the domestic environment.

One method promoting photo-sharing in the home is hinted at within Don Norman's discussion of objects that evoke memories [16]. First, Norman considers the role of keepsakes, mementoes, postcards, souvenirs, trinkets and other similar items as physical objects that symbolize and evoke memories, associations and stories [p47]. The canonical example is a trip souvenir collected during a memorable vacation and displayed in the home. Second, Norman then describes photography as yet another widespread means of capturing memories, explaining how "personal photos are mementos, reminders, and social instruments, allowing memories to be shared across time, place, and people" [p50].

Cite as:

Nunes, M., Greenberg, S. \& Neustaedter, C. (2007) Sharing Digital Photographs in the Home through Physical Mementos, Souvenirs, and Keepsakes. Research Report 2007-875-27, Dept Computer Science, University of Calgary, Calgary, Alberta, Canada T2N 1N4. July. 


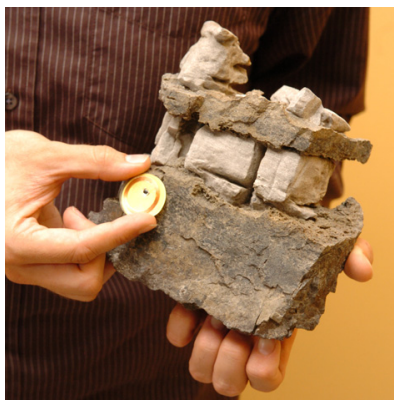

a) Tagging the rock

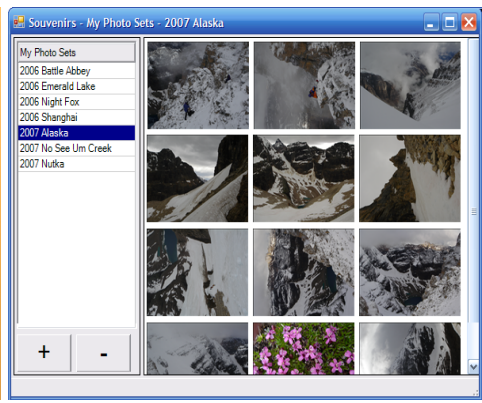

b) Adding the Alaska photos

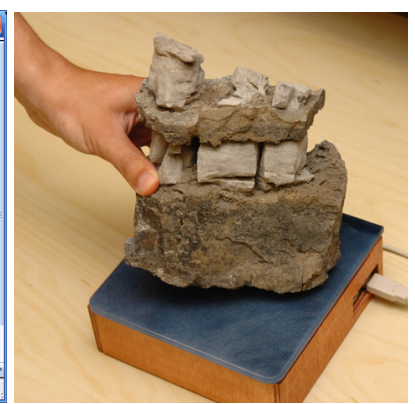

c) linking the rock to photos

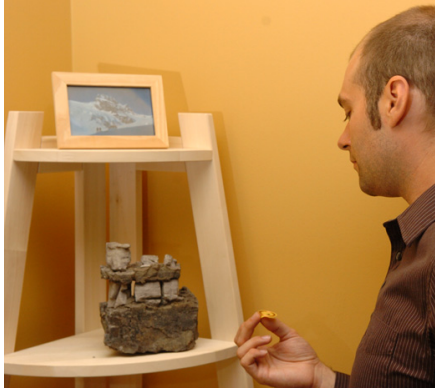

d) displaying the rock

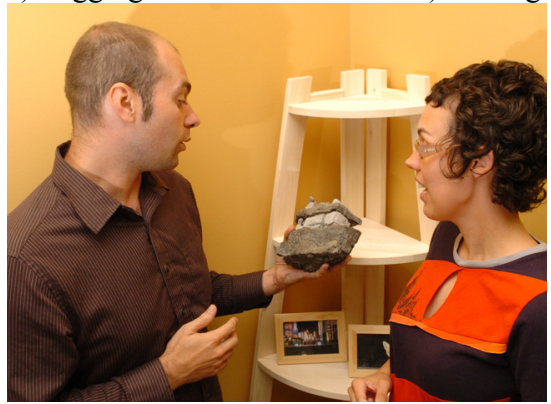

e) Conversing over the rock

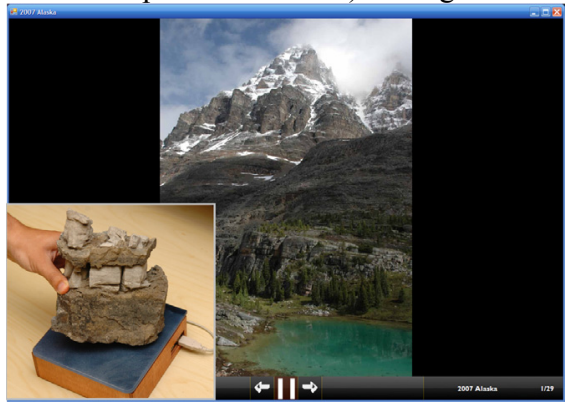

f) Starting the slide show from the rock

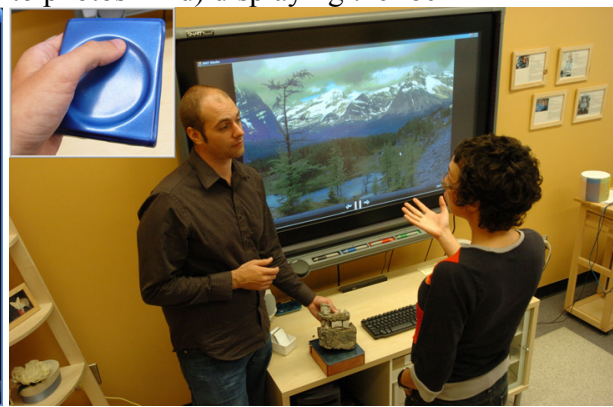

g) Storytelling through the slide show

Figure 1. Souvenirs in action. Top: linking a memento and a photo set. Bottom: Social use of the memento to activate a slide show

Norman's expository juxtaposition of physical keepsakes and photography inspired us to see a further connection between the two: we wondered if we could link these memory-evoking keepsakes to actual sets of digital photographs. The basic idea is that a person can rapidly assign a set of photos to a physical keepsake in a way that makes this association personally relevant. The person would (as normal) position the keepsake at a meaningful location within the home, which would in turn present opportunities for social engagement. From these opportunities, any household member could bring the keepsake near a large display (e.g., a Plasma television screen), which would automatically start a slide show of those related photos.

The remainder of this paper explores this idea. First, we describe our first design prototype that we call Souvenirs through a scenario and design rationale. Second, we revisit Souvenirs' design premises by conducting contextual interviews with 20 families about how they store, display and share digital photos in the home. Third, we elicit reactions from our families to a video demonstration of Souvenirs. Finally, we use our findings to critique and redesign Souvenirs to better fit the expected practices of families.

\section{SOUVENIRS}

Souvenirs is a design exploration and working implementation of a system that lets people link digital photo sets to physical memorabilia as a way to promote photo sharing in the home.

\subsection{Scenario}

We illustrate how Souvenirs works through a scenario, illustrated in Figure 1. On a recent hiking trip to Alaska with his family, Bob took many photos with his digital camera. Bob has also brought back an interesting-looking rock he found during his hike, something he does on most of his trips.

After Bob returned home, he downloaded his photos into a folder on his home media center computer that is attached to a large plasma television display in his living room. He also places the rock on a display shelf in his living room, alongside other memorabilia collected from other trips.

Bob decides to use this rock as a link to his Alaskan hiking pictures. He achieves this through the following quick steps.

1. He places a sticker (a small pre-glued RFID tag) on the side of the rock (Fig. 1a).

2. He starts Souvenirs so it is displaying on his television screen. $\mathrm{He}$ drags the folder containing his Alaska pictures onto the Souvenirs window; this folder is now ready to be linked. Alternately, he could have mixed and matched photos from several folders by dragging and dropping them into the Souvenirs window (Fig. 1b).

3. He places the rock on a platform (it contains an RFID reader) below the TV, which 'reads' the sticker identity, and associates that sticker (and thus the rock) with that photo set. (Fig. 1c) While he doesn't have to do so, he names this set 'Alaska 2007 Hiking Trip' using a keyboard.

4. He returns the rock to the display shelf (Fig. 1d).

Somewhat later, his family returns home and they have just had tea in the living room. His wife Alice sees the rock sitting on the mantle, and mentions it. Bob picks up the rock, at the same time asking if they want to see the Alaska photos (Fig. 1e). They assent, and he places the rock on the platform (Fig. 1f); the photo set immediately plays as a slide show (Fig. 1g). Through a specially designed physical scroll wheel (1g, top inset), the family can also cycle through photos at various speeds or pause them.

Two months later, Alice has a book club event in her home. Coincidentally, the book being discussed is John Krakauer's Into the Wild, a tragic account of a man who died in the Alaska outback. Other book club members have never been to Alaska, and Alice asks if they want to see what the terrain looks like. While she has no idea where Bob has actually stored the photos, she easily remembers that the rock is linked to them. She places it 
on the reading platform, and the slide show begins. After the show (and several glasses of wine), the book club members start talking about the other memorabilia on the display shelf. Alice story-tells about some of the places the family has travelled to, and selectively shows a few photos from each place by passing particular memorabilia items over the platform.

\subsection{Design Rationale}

In Bob's family, linking the rock to the Alaska photos makes it a symbolic link to those photos. Because the rock is then displayed in the home, it becomes a social instrument. He and his family can take advantage of the rock's location and visibility, without being concerned of how photos are stored and accessed on disk. The result is serendipitous photo viewing and storytelling.

More generally, the design of Souvenirs assumes that physical memorabilia can become a handle to access particular digital photo sets, just as a URL serves as a handle to rich sets of digital information. As personal artefacts, these memorabilia have physical presence, are positioned in the home in a meaningful way to its inhabitants, and can trigger recollection and storytelling in their own right. Thus the linkage of photos is a natural extension of how people associate memories with the artefact, as is the lead-in through opportunistic story-telling.

Of course, paper-based framed photos and photo albums serve similar purposes. The power of Souvenirs is that it works without requiring the home occupant to print and organize their photos, an operation that is increasingly expensive given that people take and store many more digital vs. film photos. In its stead, a single physical artefact serves as an access point for a photo set.

Souvenirs facilitate other aspects that distinguish it from conventional digital photo showing.

Access control problems disappear. In many homes, each family member may have a personal password-protected account on a home computer. While a person may not intend to limit access to their photo set, the placing of photos in a personal account means that other family members need to log into that account. Souvenirs is constructed in a way where photos are published in a public file store accessible by the underlying software.

Navigation problems are circumvented. In practice, accessing digital photos is tedious, typically requiring one to $\log$ in and navigate a set of folders (or a long list) containing the photo sets, perhaps catalogued by special software. Navigation problems arise when the photo set owner cannot recall where he or she filed particular photos, or when other people do not have the knowledge of where these photos were stored or labelled.

Time delays disappear. With standard digital photos, people have to stand around and wait as: one person (usually the photo taker) turns on and logs onto a computer; navigates through a traditional GUI system to find the photo set; starts the software and navigates through its controls to display the photos as a slide show. With Souvenirs, Bob simply brings the rock to the display and the photos are shown immediately.

Viewing is in a social setting. Groups no longer have to view photos by crowding around small desktop computer displays located in out of the way corners of a home such as in a den or bedroom office. We assume that Souvenirs is permanently linked to a large display - a new generation television set such as a 50 " plasma display - located in a public home space such as a living room. Unlike home offices or spare bedrooms, these rooms and the display are already set up as a social space. Family and visitors regularly inhabit that space (which creates social opportunities), and the display is easily and comfortably viewable by all (e.g., televisions are normally surrounded by couches).

We partially implemented Souvenirs, and then created a video that demonstrates what it would be like to use it in a home context. As will be described in Section 3, we showed this video to participants in a study, where we wanted them to react to the Souvenir design idea. In turn, this information would give us insight into how it might be used (or not used) and improved.

\subsection{Hardware/Software Setup}

Souvenirs comprises a large screen plasma display to display photos, a base containing a Phidget RFID reader [9] to read the tags attached to the mementos, and a Phidget circular touch scroll device[9] for manually scrolling through the on-screen photosets. Clear thin RFID tags with sticker backing are used to tag the physical mementos.

The software is similar to conventional photo showing/viewing software in that it lets a person import folders and individual photos into photosets via drag and drop, manually scroll through these photos, or start a slideshow. It differs from conventional software in that the person can link the photoset to the physical object with an attached RFID tag by placing the object on the base. When the RFID tag is read the software links the two by storing the RFID tag ID as a handle to that photo set. When the object is again placed on the base, the RFID tag ID is recognized and the system brings up the associated photo set. Finally, the circular touch device invokes manual backwards and forwards scrolling, and an automatic slideshow display by double-tapping.

\section{CONTEXTUAL STUDY}

So far, our work is design oriented: we were inspired by an idea, developed a design rationale, and built a $1^{\text {st }}$ version system to help us understand its nuances. Our next steps were to: gain a better understanding of people's existing practices around film and digital photos; understand how people used and stored mementos in the home; get people's reactions to the Souvenirs concept and how it could be improved. To achieve these steps, we conducted in situ contextual interviews with 20 families. These examined family routines for how they stored and shared photos, how they used mementos, and their reactions to a video of Souvenirs in use.

\subsection{Participant Households}

We recruited 20 households that spanned a range of lifestyles, occupations (e.g., dentists, graduate students, professors, sales engineers, bank managers, etc) and ages (from teenagers to adults in their 50's). Households also ranged from having no children to having at most two, yet our selection was intentionally biased towards 'family' homes (either with children or young couples) as they would be most likely to have a desire to participate in photo sharing activities within the home. All households took pictures on a regular basis on at least one camera.

\subsection{Method}

We used semi-structured interviews (children under 14 years were not interviewed). Interviews were held in participants' homes as this would allow them to recall and describe their routines for photograph and memento storage and sharing in context. It also allowed us to gain a first-hand view of how these practices fit in 
the domestic environment. We first asked household members how non-digital and digital photos were organized, displayed, and shared within and outside the home. Next, we asked household members what types of souvenirs or mementos they collected, what memories were associated with these, and how they displayed them in the home. To ground our interviews within actual practices, we asked participants if they would show us (and if we could photograph) the location and the types of photographs and souvenirs they kept. Finally, we showed families a video demonstration of Souvenirs. They told us what they thought of it, how they might see themselves using it, and what they disliked or might want to see changed or added to it.

\subsection{Data Collection and Analysis}

All interviews were audio recorded and handwritten notes were taken to aid analysis. We used an open coding method [20] to analyze this data, and generated a large amount of codes that reflected a variety of household routines. We then used affinity diagramming [10] to categorize these codes and pull out important themes. These themes, rather than the individual codes, form the heart of our result section. Our findings are presented in three parts: use of digital $v s$. print photography, use of souvenirs and mementos, and reactions to our system design.

\section{DIGITAL VS. PRINT PHOTOGRAPHS}

For the first part of our study, we briefly compare print and digital photography. As we will see, our study verifies prior findings in photo organization and sharing practices; we include references to key papers as needed.

For our purposes, we distinguish photographs in terms of how they are stored $v s$. how they are taken. During our interviews, we found that people discussed photos based on how they are stored and used, rather than on what camera (digital or film) they used to take the photograph. In particular, families who maintained print photo albums after switching to a digital camera treated them as print photos, and often had only a fuzzy idea of which prints were originally film or digital. Similarly, those who scanned in old prints as digital copies treated the scanned items as digital photos.

The only notable difference in the source format change is that most families said they took many more photos with the digital camera (because the cost was essentially zero). This often resulted in multiple photos of similar shots [11][12], or that more everyday events or subjects are deemed worthy of a photograph [12].

\subsection{Organization and Location}

Storage methods for print photographs typically consisted of photo albums, photo envelopes, and photo boxes [8]. Photos in these collections are usually organized chronologically, or by event, or some combination of both; however, the amount of explicit 'organization' varies considerably. Time often serves as the primary organization, as photos are, by default, organized and grouped chronologically when they are developed.

Print photo collections are stored in various places around the house, the most common being an office or living room shelf. They also show up in bedrooms or basements, in closets or cabinets or other places. When asked why the photo collections albums, shoeboxes and/or envelopes were located where they were, participants stated that this was usually a function of finding adequate space and avoiding clutter.
"Um, they took up a lot of space, and we don't have a lot of storage space. So, this is just where it ended up."- P4, Wife

Some, however, did note that locations were chosen to be easy to get at when guests were around, but this did not seem to be the primary motivation in choosing the location.

"I suppose partially because there's room for them, and also because this is where the guest sleeps..."- P9, Wife

Individual photos are often placed on display, generally in a picture frame on walls / shelves. Location choice was determined by a combination of space availability, aesthetics, and visibility.

"I thought this was a good spot. It's just for us, it's not for showing off, you know. I just thought this was a good spot for the size of the picture." - P1

Digital photo collections, unsurprisingly, were mainly kept in folders on a computer. All but one simply used the file system rather than special purpose software for organizing photo sets, saying this was adequate. This was in spite of the fact that participants reported using external software for photo editing, or uploading photos to a website or email. Some also kept copies of photos on an online site as it allowed for easier sharing.

Several participants regularly stored photos on CDs or DVDs. One reason was to simply back up their collection as a copy. Another was to use the CD/DVD as the primary storage, where they removed their photos from the computer to minimize hard drive clutter. Discs were generally stored near the computer [12].

Digital photos were typically organized in folders via some scheme that used events and dates [12][13]. Akin to photo envelopes, folder contents often reflected how they were downloaded from the camera.

"In a way digital is nicer because you don't have to [sort and label them], you just save it and it's there. You don't have to manually go through and then put them." - P5, Mother

\subsection{Accessibility}

Next, we wanted to determine the roles played by family members in storing and organizing the photos. Specifically, we wanted to see: if there was a primary photo organizer; if knowledge of photo collections was largely relegated to that organizer; and whether other family members shared knowledge of these collections. If the last point was true, this would allow a particular member to recall, find and show photos stored and organized by someone else. We expected significant differences between print and digital photo collections.

Print photo collections. For families with children, we found that the organization of print photo collections, such as photo albums, was primarily undertaken by a single parent - usually the mother - although others would sometimes help in the organization. Even so, most other family members knew about these collections and how to access them. Households consisting of younger couples differed: each participant typically kept their own print photo collection, and their partner's knowledge of that collection varied.

Digital photo collections containing family pictures were also maintained by a single parent in a family with children, but this time more often by the father. In contrast to print photos, knowledge of collections was generally limited to the person who had organized them. While some family members may know that a photo collection was being kept, they often did not know what was there or how to access them.

$D$ : [after showing Mom some folders containing photos] Did you know that? M: No, I don't use that, I don't know." - P1, Mom and Dad 
Even when a person had an idea where photos were, they were reluctant to go onto the other person's computer.

"I'll use [my husband's] computer but it's his computer so I would like, I know his password but it's like his space. And my computer is my space"- P4, Wife

As a consequence, people often resorted to the social channel, i.e., asking one another, when they wanted to see particular photos.

"Absolutely. I don't think they even know about the organization. Usually when they wanted some, like sometimes, you know, for her project, she'd ask 'Mom, can I have', you know, a picture of her in an occasion or something like that. And then I will find it and I will get her a copy."- P8, Mom

There was only one case where these photos were maintained collectively, where the family chose to maintain collections in the common root folder $\mathrm{C}$ : / photos. Most others used a folder held within a user account, typically My Documents/My Pictures. However, older children (e.g., teens) who took photos tended to maintain and control their own digital photo collections quite separately from the family collection.

\subsection{Why and How People Show Photos}

The methods for sharing. We saw 3 primary methods that families used to share photos in the home [2], each method usually accompanied by a different reason for sharing.

1. Displayed photos are those placed out in the open for all to see, typically in frames hung on walls or placed on shelves. These photos are readily noticeable by anyone within their general vicinity and in this way can be shared implicitly.

2. Shown photos are those that an owner brings out specifically to share with others, e.g., a print album of vacation pictures taken from a shelf and shown to guests, or a wedding slideshow (slides or digital) shown to relatives.

3. Gift-giving photos are given as gifts to the recipient. Gift giving does not necessarily involve face-to-face sharing. Examples include mailing or handing off printed doubles, or emailing digital photos to friends.

For displayed photos, family members typically chose photos based on aesthetic $v$ s. communicative reasons. That is, they chose personally favorite photos that would display well, rather than ones that would evoke story-telling with guests.

"Everyone has their favourite ones that they want to print and display. In fact I have a bag of negatives because I think - this is just a rental property - but I think I'm gonna have a house someday, and I'm gonna want to blow this one up and frame it. So I have those still. I save all my negatives of favourite pictures"- P17 Wife

For shown photos, we asked family members about why they showed particular photos to guests [2]. Their reasoning typically included the guest being in the pictures, or the guest having shared the experience or event shown in the photos, or that it led naturally from social relevance (e.g., conversations about particular vacation destinations). Thus the particular guest and the course of conversation are the primary factors, rather than simply showing some recently liked photos.

"If I took a picture of someone then l'd show them the picture, and if it was from a vacation then I might show anyone who was interested."- P9

"Just if we thought it would be interesting to someone else. Like if there are people we did sports with or hiked with we, like camping or whatever, like our mountain trips. Or if we're travelling somewhere - someone that's interested in hearing about the trip, we'd show."- P5, Father

For gift-giving, participants often stated that photos were chosen and given as a 'status update' to infrequently-seen family and friends, i.e., to provide interpersonal awareness to intimates living outside the home [15]. Photos typically illustrated recent life events, or presented newer photos of children growing up.

"My parents...anytime they take pictures they make us copies ... and we get copies of our nieces and nephews or our kids that they've taken. Usually it's kid related." - P5, Mother

"I was living in a resort at the time, so I was sending them to my family and sharing them with them that way...I would send the scenic pictures because, of course the mountains are so beautiful. And I would also send them, like if I had a friend I talked about a lot, I would send 'oh, this is... we work together' and I would always write on the back of the pictures."- P17 Wife

Print vs. digital. The differences between print and digital photos affect how people share photos. At one extreme, physical prints are currently more amenable as displayed photos. While digital photo frames are beginning to appear, they are still expensive and constrained by power, lighting conditions, and limitations on how they can be positioned in a particular space. Only one of our families owned a digital photo frame, and they stated that this was kept 'off' most of the time. Still, two participants noted that they used their computer's desktop wallpaper or screensaver to display a digital photo, but of course its placement was restricted to that computer's location. At the other extreme, digital photos are seen as much more effective for gift-giving. Compared to the cost and effort of print duplication, it is very easy to email others photos and links to online albums. Shown photos are still amenable to both print and digital media; while many participants liked showing slideshows on computers or laptops, those who maintained print photo albums preferred to show those.

Of course, new cultures have emerged around sharing photos on web sites such as Flickr [13]. This is akin to 'displayed photos' as it is centered on sharing aesthetically pleasing photos, although often with remote strangers.

Printing photos from digital media. Notwithstanding the above, we were somewhat surprised by how many people still chose to print photos that they had taken with a digital camera. For most, the affordances of a paper print, especially for showing, was superior and still had great appeal for the reasons provided below.

- Easy viewing. "I find that if I take any digital pictures I still want to print them. Cause, well for me anyways, I like to look at a picture rather than a computer you know"- P3, Daughter

- Easy showing. "And if you want to show them to somebody it's harder, cause you have to bring them to your computer or burn a $C D$ and take it to them. It's a bit more effort than just envelopes." - P4, Wife

- Socially engaging. "I really like having them there to look at... just having it more like a book so you can socially sit and go through things with like my mom and friends." - P5 Mother.

"I really like to be able to grab something and hold on to it and look at it and pass it around. Where, the digital, you stick it all on a CD and it takes less space, but you don't do anything with them." - P16 Wife

- Location. "You've got to go to the computer right, you can't just go to the kitchen table with it. Which is where - we had my birthday party, remember, where'd everybody hang out? We've got all that space and all that space and everybody was just right here. Unless you have a laptop with wireless, which we don't have..." - P16 Husband

\subsection{Discussion}

Our families' use of print and digital photos had much in common with families studied by other researchers. In turn, this suggested that our motivation for the Souvenirs system was valid. In particular, people's digital photos, unless printed, had significant problems of accessibility. Unlike print photos, especially those kept in photo albums, they were essentially hidden away in the photo organizer's personal file system. Yet printing, organizing and displaying all photos taken with a digital camera is not a reasonable option for most. It is expensive, and it does not scale well to the myriads of photos that people now take. 
We also saw that people share photos for different reasons and using different means. In the digital realm, gift giving is already well handled by asynchronous messaging systems (email, instant messengers) and by special purpose web sites. Displayed photos are now being addressed by digital photo frames, although its general acceptability still has a long ways to go. Shown photos are the 'sweet spot' for Souvenirs, where it could promote easy sharing of digital photos in a socially engaging location.

\section{SOUVENIRS AND MEMENTOS}

Next, we interviewed participants about their memorabilia collections to find out what types of items were kept, where they were kept, and what meaning was associated with them. Our goal was to understand how such memorabilia could be used by Souvenirs for linking with photo sets. Overall, we found that people had four main categories of items. We classified these as: collectibles, wearables and consumables, personal accomplishment, and trip output, detailed below.

\subsection{Collectibles}

Collectibles are souvenirs that represent places or events (Figure 2). As a group, collectibles contain by far the greatest variety in types of items. Examples include things such as decorative or artistic items from a place, statues, rocks, or postcards. Collectibles can be further broken down into individual or group.

Individual collectables are typically one-off items chosen to represent a specific place or event. They tend to be decorative, as exemplified in Figure 2a.

"It's a bouquet of tulips. That would represent our trip to Holland because Holland is known for their tulips. And the reef shark there represents our trip to Fiji because we saw a lot of reef sharks...the didgeridoo, you look at it and you automatically know it is from Australia... at least I do."- P11 Wife

Group collectibles are items where the owner has a special interest in a certain type of object and seeks to form a collection of them. Some were from trips the collector had been on personally (e.g., Figure 2b), while others were gifts from friends who knew that the person had an interest in that type of item. Examples include money, stamps, postcards and even souvenir pins from various countries (Figure 2c).

"My husband especially likes to collect stuff. He wants to do a map and have a coin from every country." - P3, Wife

People largely located collectibles for pragmatic reasons, i.e., where there was adequate room to display it, or where it fit in with the décor of the house. Aesthetics and the type of collectable play a role. In particular, individual collectibles tend to be decorative and are often found on public display, e.g., hung on walls, in bathrooms, or on shelves and mantles. Figure 2a gives an example of how individual collectibles are displayed as public artwork. Because group collectibles tend to consist of many small items, people often kept them together in some out of the way place such as a drawer. For example, Figure $2 \mathrm{c}$ shows how one family located their souvenir pin collection in a special drawer. Yet people do put some group collectibles on public display: Figure $2 \mathrm{~b}$ shows one family's rock collectibles, each gathered from hikes and later painted, that are displayed on the fireplace ledge, while Figure 2d shows a collectibles display cabinet.

Families often thought of collectibles as conversation pieces when showing others around their home. Items would trigger memories of an event, sometimes leading to storytelling or discussion.

"When you walk into someone's house and you see something that you

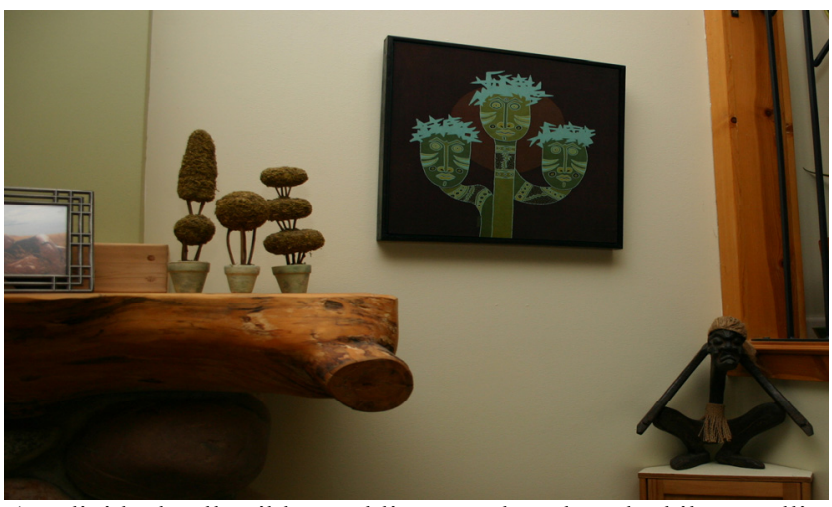

a) Individual collectibles: public artwork gathered while travelling

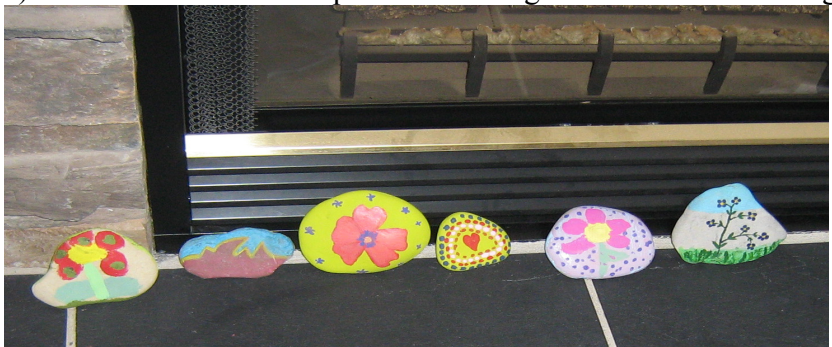

b) Group collectibles: rocks gathered from hiking trips \& painted

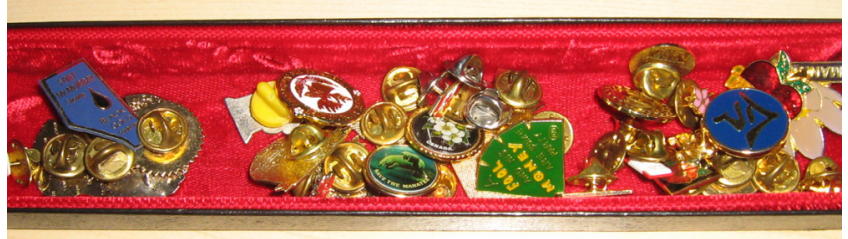

c) Group collectibles as souvenir pins kept in a drawer

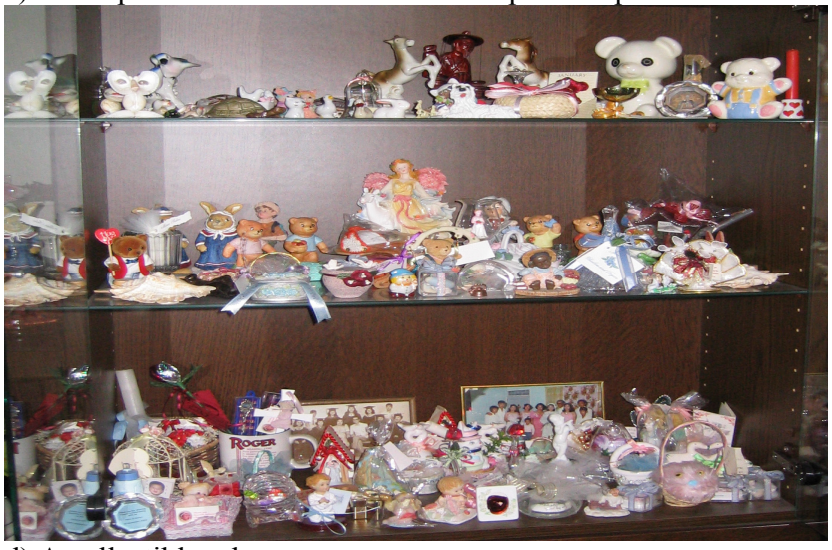

d) A collectibles showcase

Figure 2. Examples of collectibles

know is from somewhere, that's gonna start a conversation too. We got a map out there that I got framed from when [my husband] went to Fiji...that's a conversation piece. People say, 'where did you get that?'”- P11, Wife

\subsection{Worn / Consumed}

Worn or consumed mementos include items such as clothing, accessories, or food that are representative of the place they are from. For example, one father told us how he would routinely bring back chocolate from his travels, as he found chocolate differed between region or countries. While closely tied to the places where they are from, these items are picked up for a more practical reason: to be eaten or worn. Given this, we expect such 
items are inappropriate for photo linking.

\subsection{Personal Accomplishment} Some mementos commemorate personal accomplishment activities such as sports or performance. Typical items include team photos, trophies, plaques, medals, or

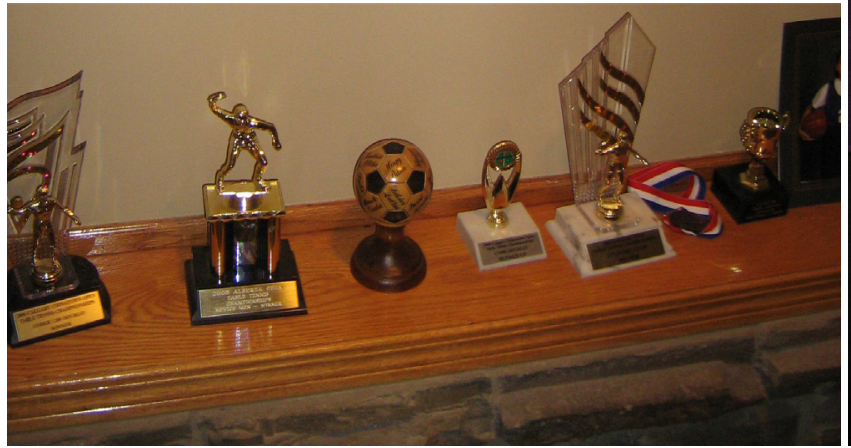

Figure 3. Personal accomplishment: Basketball trophies

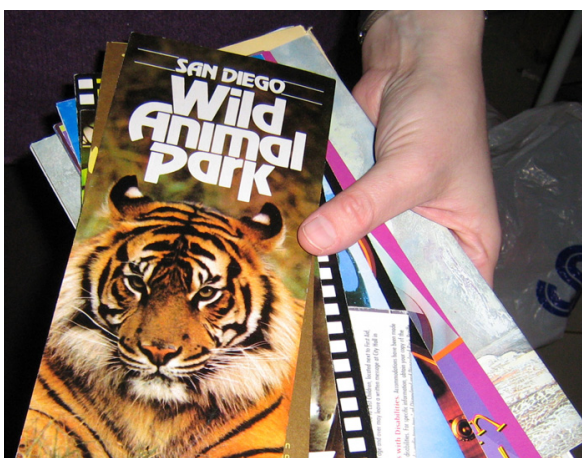

Figure 4. Trip output. certificates for activities such as sports or musical performance. They are usually placed for display on a shelf or wall, and often related items are kept together. For example, Figure 3 shows a shelf in a child's room that contains all her trophies and awards.

\subsection{Trip Output}

The trip output category includes items accumulated as a result of a trip. Typical examples include tickets, maps, or pamphlets from various places that have been visited or events that have been attended (Figure 4). They can be considered a variation of group collectibles, although more for future reference and reminding than as a displayable souvenir.

"I think I collect everything. I keep ticket stubs, receipts, brochures, and sugar packages...Originally it was because of the scrapbooks because I knew l'd have a way to save them all. And I guess it just invokes more memories of the vacation...sometimes they're funny or interesting."

Trip output is often kept together, usually in some out of the way place or in a box. For example, one family had a large bin in their basement that kept all of the maps and brochures from the band trips the husband and wife had taken. For most, trip output items had no real practical purpose after the trip, yet many cited that they could not get rid of them because they served as reminders and memory triggers of particular events and trips.

In some cases people stored some of their smaller trip output items within the paper photo album. They liked that photo albums allowed them to keep these forms of memorabilia alongside their corresponding photos.

"I like the ... albums because I can put all the other little stuff that I keep, like tickets and posters and pamphlets and stuff, I can put them right in with the pictures." - P4, Wife

"For one trip I took I stored things in a scrapbook, and I liked that because then I could also keep tickets and brochures and things - other things in the same place as the photos."- P9, Fiancée

\subsection{Discussion}

The several types of souvenirs and mementos suggest both opportunities and concerns about our idea of using physical objects as links to photo sets. On the positive side, individual collectibles are perhaps the most amenable to Souvenirs, as they clearly associate mementos to particular events. It is also clear that some types of group collectibles, trip output, and personal accomplishment are also suitable. For example, trip outputs are small and often kept together, making it easier to find a particular item. They already serve as memory triggers for a trip or event.

We also saw that people group certain types of mementos, and this in turn suggests that we could exploit this grouping. For example, the way people sometimes keep related trip memorabilia within a photo album or group collectibles within boxes suggests that one could create special purpose 'souvenir albums' and 'souvenir boxes'. These could contain souvenirs that represent collections of photo sets, where individual items would activate the display of a particular set. The downside is that these items may be stored in out-of-the-way places. However, frequent use of them as part of the Souvenir system may cause them to be moved to more convenient locations.

We also see several problems. It appears that items are often spread around the home or sometimes nailed to the wall, or they may be too large or too fragile to move. These affect our premise that mementos would be located close to a large display, where they can be moved to that display to trigger the appearance of an associated photo set.

Some mementos are fairly general, and thus it is somewhat unclear how they would be associated to specific photo sets. For example, a child's personal accomplishment trophy awarded at the end of a basketball season could be potentially linked to many different things: photos of the entire season, team photos, the winning game, or photos of the child playing. This variety may easily cause confusion for creating or remembering associations.

\section{SYSTEM AS TECHNOLOGY PROBE}

Finally, we showed participants a video of the Souvenir system as described in Section 2. We wanted to elicit their reactions to the system, find out how the system might be useful or challenging, and gathered suggestion of how to improve it.

\subsection{Sharing and Tangible Icons}

Participants had positive reactions towards Souvenir's affordances for digital photo sharing within the home, and the use of tangible icons for retrieving photo sets. They liked how the system was situated in the home's social context, i.e., the use of the large television display in a public home area to show the photos, and how this setting created an opportunity for multiple onlookers to view and discuss the photos. As one participant put it:

"That's something l'd show friends. More friends can watch at the same time, not like an album where only a maximum of two people can look at an album. I think it's good." - P1, Mom

Additionally, people liked how Souvenirs hid the technology and the tedium of retrieving and sharing photos as compared to traditional computer navigation. They liked how it was immediately 'ready to go' at any time, and how it avoided the need to navigate and invoke applications to show digital photos. Some saw this as particularly useful for picture-showing by elders who could have trouble with conventional computers.

"Where it would be useful is for the parents and grandparents. If they could 
just do that to their TV. Nevermind the issue of having to transfer all of the pictures over. Once it was setup then yah, my parents could just wave an object." - P7, Husband

"I guess if you found an object to link it to or a picture it would be really easy to find an album. And because it is already connected to the TV or a big screen it is easier than connecting the camera." - P9, Fiancée

People were generally receptive to the idea of using physical items as a link to retrieving photo sets. They said this would allow sharing 'by chance' (serendipity) from displayed memorabilia. They liked the novelty of physical linking, and thought it was something they would want to show off to friends. They thought that linking photos to physical objects would be easy and would make finding / displaying photo sets quicker and more enjoyable than with traditional computers.

"It seems a lot more fun and interesting to have a symbol from the actual place rather than having to go on your computer and start clicking on folders. They are a lot more organized this way and there'd be more memories." P3, Teenage Daughter

"You don't have to sit down and try to find the picture you want to show friends, it's just there." - P1, Dad

\subsection{Challenges}

Participants also noted several concerns about the Souvenir design. These are important, as they suggest redesign directions.

Fit to existing practices. Families stated that the utility of physical memorabilia as a link to photos depended on the actual practices they used to display souvenirs and mementos in the home. Some noted that they preferred not to have many mementos displayed around the home for aesthetic reasons, and thus questioned the usefulness of physical icons a links. In those cases, they still thought the large public display was very desirable.

"I would like it if all of the pictures that I had on the computer were on the TV and I could scroll them, have a remote, and look through them. That would be great. Linking them to objects would be trouble for me because I don't like to keep those kinds of objects... that part of it wouldn't work as well for me...just to be able to turn it on and have them sorted chronologically or by event, you could see all the birthdays, or Christmases, or holidays. It would be just like on the computer, but on the TV instead. You could assign tags to pictures and just have it organize them automatically. You could almost have a playlist of photos that you could look through." - P13, Husband

Scalability was a related concern. People who did keep mementos were worried that religiously linking photos to physical mementos kept in accessible places would eventually lead to clutter and storage problems. They stated they took and maintained large collections of photo, which would exacerbate this problem.

"You would have to remember to get something each time...after a while you'd need a large storage area beside your big screen TV. For me, I was in Italy I don't know how many years ago I brought back that porcelain doll so l'd have to store a lot." - P1, Dad

"The amount of pictures that we take, we'd have boxes of items, you'd be literally grabbing things from boxes. For us I think a big screen like that if you could hook it up to this [remote]. The biggest problem we have is crowding when we show photos, but to be able to put that stuff on to a bigger screen would be good."- P16, Husband

However, people suggested a partial solution to this problem. As well as physical mementos, they wanted the option of having an 'index box' containing single physical photos, each tagged and thus linked to its associated digital photoset. The box would allow many tagged photos to be kept together without clutter.

"I'd have a hard time finding and storing those objects. Where would I put them all? One picture for each set would work."-P2, Mom

Others noted that an on-screen photo list might be as effective.

"The object thing is the thing that l'd find hard because you want to have the objects close to your TV and stuff...l'd just like to go wedding photos and have them pop up like that. l'd almost rather have folders where you could just touch, but we're not really souvenir-type people... I guess a box of cards would work, but if you're just going to do that you may as well have folders on the screen"- P7, Wife

Appropriately associating physical items to photos was another concern. Some thought they might have difficulty finding a memorable item that appropriately links to a given photo set. In some cases, there simply may not be any relevant item available.

"The only thing is it applies more to pictures from something special like maybe a party or wedding where you could have something that triggers the pictures. But with just regular family pictures it would be hard and sometimes you do take a lot of those pictures, and sometimes you do want to retrieve some of those pictures."- P8, Mom

"For the Turkey trip, we could link that [points to an item brought back], but for family photos it would be trickier to find something."- P9, Fiancé

Some also mentioned that the association between an object and a photo set may not be known to other members of the family. This would make it hard for others to find a set of relevant photos.

People also wondered if they would forget the association between a given memorabilia and its photos. Some even suggested writing descriptions on the physical items.

"Over time you might forget what souvenir was attached to what group of pictures, especially if you went somewhere twice. Like if you went to Seattle twice and took two sets of pictures. It's a good way to remember but also not organized enough for me. l'd maybe just have a normal object, like a stick with a sensor, then you could write the date, time, and event name and then just put that over the sensor." - P14, Wife

Breaking and losing mementos. Participants were concerned that moving physical mementos around to use as links to photo sets would increase the risk that fragile items could break, or expensive items lost. If this happened, they were also concerned that those photo sets could then become inaccessible.

"So what happens if you lose the object that has the tag on it? Do you lose the photos?"-P1, Dad

\section{Discussion and System Revision}

Many of our findings supported the Souvenir design. However, they also introduced concerns. Here, we describe how several of these concerns resulted in design changes.

Creating public photo sets. While people said they liked the idea of accessing photos from their TV (as well as from other computers), this begs the question of how the photos get there. The issue is that people, by default, store photos in their own accounts rather than in a public place, and that they likely will want to share only a subset of their photos rather than all of them.

To solve this problem, we revised Souvenirs to work across all computers on a home network, where shared photos are copied to a public folder. People start the photo management view of Souvenirs on a particular computer and account where they store their full photo collection. Similar to other photo management software, this view allows them to create new photo sets: sets are displayed as a list, and photos are represented by thumbnails. People add photos by dragging and dropping files or folders into this view. If they have an RFID base attached to this particular computer, they can optionally associate a photo set with a tagged object by passing the object over the base as usual. Under the covers, as photo sets are added, photos are copied to a shared public folder alongside meta-data about their associations. Photos and meta-data are now available to other connecting Souvenirs clients. At this point, other family members can view, modify or even remove these photo sets as desired. 
Memento linking is optional. It is unrealistic to expect every single photo set to have an associated physical handle [12]. Somewhat similar to how people currently create photo albums around specific events or favoured photos, we now expect people to selectively choose photos to share and link, where a large bulk of photos will be left behind. As originally described, Souvenirs already allows photo subsets to be added to it. In our changed version, only these selected photos are copied to the public folder.

We also changed Souvenirs so that people, by default, could access and display all photo sets through on-screen navigation. They use a photo
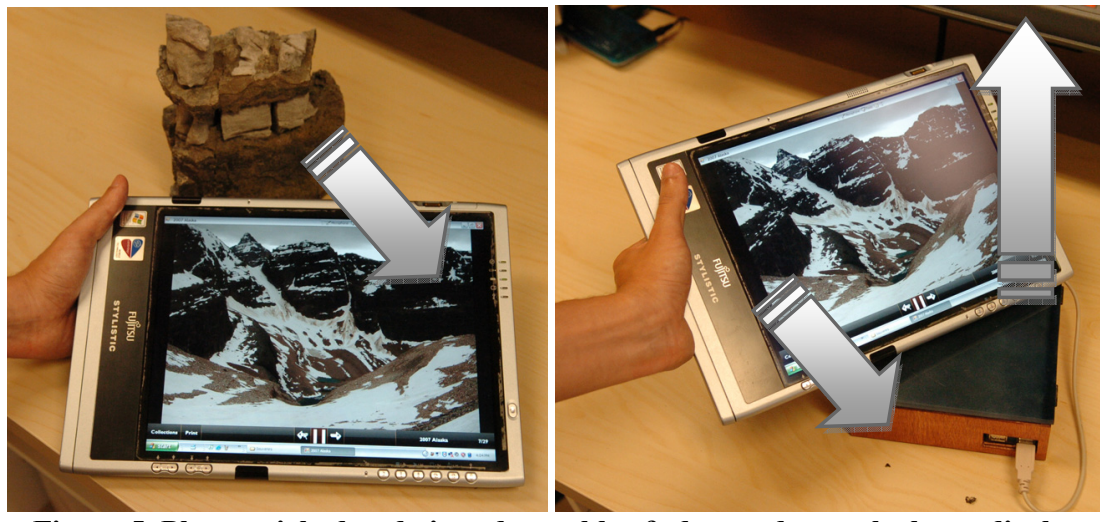

Figure 5. Photos picked and viewed on tablet \& dropped onto the large display management view similar to Figure $1 \mathrm{~b}$, which lists photo sets and thumbnails. To start a slide show, users navigate and select a set from this list using standard input devices or our physical scroll wheel control. Thus people can share a photo set without requiring a tagged object - which will be useful in the case the tagged object has been broken or lost, or when people have forgotten which object is associated with a photo set, or when no associated object is available.

Yet at any point, people can decide to create a physical link to a photo set by dragging a tagged unassigned memento over the reader. In this way, people can adopt the technology to best fit their practices, using mementos as little or as much as they want.

Using other physical objects as links. People suggested that mementos were not always practical, e.g., because of size, or fragility, or because no memento is available, or because they are hard to organize. They also suggested other physical objects would be suitable, such as printed photos and index boxes.

We modified Souvenirs in two ways to make it easy for people to create custom mementos that can be linked to digital photos, where these custom mementos are easily organized. First, Souvenirs now comes with a dedicated small photo printer and sticky-backed RFID tags. At any time, a person can quickly print an exemplar photo from the photo set being viewed and stick an RFID tag onto that print. Second, we also supply people with credit-card sized RFID cards and a marking pen. People can annotate these cards with written descriptions and text. For both print photos and cards, people then quickly link them to a photo set by passing it over the RFID reader. Both print photos or cards could perhaps be stored and organized in time/event order in attractive boxes kept next to the display, or in booklets dedicated to particular types of events, or (for photos) even within photo albums or framed on a nearby photo wall.

Using other displays, particularly mobile ones. While we envisaged Souvenirs as running on the public television screen, it became apparent that this was overly restrictive. Some mementos aren't movable, either because they are fixed in place, or are too large or heavy to move, or are too fragile, or are too far from the public screen. Clearly, people need to be able to view photo sets associated with such objects spread around the home. As well, there may be opportunities presented by computers in other home locations. While these obviously include personal computers, we are especially interested in mobile displays such as laptops and tablet PCs, as these can be moved around the home.

As mentioned, we modified Souvenirs so that it works over a home network, where photo sets are stored on a central server. Consequently, people can now access Souvenir photos from any computer on that network. As a Souvenirs client connects to the server, all new photos since the last connection are cached on the local computer to make navigation and display responsive.

For mobile computers, we equip them with a small Phidget RFID reader [9] (we tape one on the back of a tablet PC). This means that Souvenirs no longer demands that the memento be moved to the large screen. Rather, we can move the tablet PC to the memento, and the associated photo set is brought up in the slideshow view (Figure 5, left). People could then gather around the tablet to view the slides.

The small screen size and limited viewing angle of most mobile devices means that they are comfortably viewed by perhaps two to three people. For larger groups and for easier viewing, we still believe that photos are best seen on the large display. To ease this transition, we allow the mobile device to act as a go-between the tagged artifact and the large display using a 'pick and drop' strategy [17]. After a mobile device raises the photo set associated with a tagged object (Figure 5, left), the device can be brought to the large display, and the photo set will then appear on that display (Figure 5, right). An RFID tag is embedded on each mobile device. When a photo set is selected on the mobile device, the device's tag is temporarily associated with the chosen photo set. In this way, the device can be passed over an RFID base attached to the large display and the photo set will be triggered.

Remembering and knowing associations. Another concern was that people said they may not know or remember what a physical item is linked to, especially because the item does not 'show off' the fact that it is a link. While we speculate that shared knowledge would develop as items are displayed and families adopt the system, we do not have a clear solution to this problem. We hope to encourage discoverability by making it easy to 'explore' a room with a mobile device to discover mementos and their associated photo sets. However, the issue remains that these objects do not directly show that they are being used as links particularly as they might co-exist with other displayed memntos which are not being used in this way

\section{Related Systems}

There are myriads of systems dealing with photowork [12][13]: the process of how people deal with digital photos up to but not including sharing photos with others. Software includes photo alterations and stitching, organization, browsing and searching, 
and clustering by various mechanisms. These systems are not reviewed here, as Souvenirs is primarily concerned with the subsequent photo sharing step.

The idea of using tagged physical objects as handles to electronic information is well known in the tangible and ubiquitous computing fields. In particular, Memodules [14] is a framework for prototyping tangible interfaces by allowing links between RFID-tagged physical objects and actions taken in the digital world. For example, they describe how a colleague's business card can trigger actions such as opening up an email composer to that colleague, and they also mention linking souvenirs to photo sets. However, their focus was on presenting their technical framework, while ours is on the detailed design rationale of how people might use such a domestic technology.

Additionally, [7] looks at how physical memorabilia is used to retain memories in the home, and presents two systems that support storytelling around these objects. The memory shelf links an object to a recorded audio message. The anniversary plinth prints out a textual record of the objects history. Neither draw the link between photos and memorabilia.

Various researchers have also considered collocated storytelling over digital images through specialized devices. One prototype is a handheld device that lets people browse, view, author and show photos [1]. Similarly, we know that people sometimes use the preview mode of their digital cameras and cell phones to show particular photos to others. Another example is special software for photo sharing over digital tables [19]. All these systems emphasis storytelling within a photoset, while Souvenirs is centered around bringing particular photosets into action. Thus the works are complementary.

\section{Conclusion}

We have presented the Souvenirs system, its design rationale, and a contextual study of everyday practice along with an exploratory technology probe. Souvenirs presents a novel method for photo sharing within the home, while our study has validated several of the design goals behind Souvenirs and, perhaps more importantly, suggested ways in which its design could be improved. More generally, this work outlines how one can begin to envision a home where in-home photo sharing, or indeed sharing of any digital materials, moves away from the desktop PC and into the social fabric of the home.

This paper is best considered as a design rationale, a requirements analysis, and a technology probe. We still have to confirm if Souvenirs would be adopted in a home's culture. Our next steps are to try out Souvenirs within our own homes (to spot any large problems), followed by a field deployment and study of its use.

\section{ACKNOWLEDGMENTS}

Jeni Lynn Vito interviewed families for our pilot study. Research is partially funded by Canada's NSERC Discovery and NECTAR Networks Grant program, by Alberta Ingenuity, and by our industrial sponsors SMART Technologies Inc. and Microsoft.

\section{REFERENCES}

[1] Balabanovic, M., Chu. L, and Wolff, G. (2000) Storytelling with Digital Photographs, Proc ACM CHI'00, 564-571.
[2] Chalfen, Richard (1987) Snapshot Versions of Life. Bowling Green, Ohio: Bowling Green State University, Popular Press.

[3] Crabtree, A. and Rodden, T. (2004) Domestic Routines and Design for the Home. Computer Supported Cooperative Work, Vol. 7, Kluwer, 191-220.

[4] Crabtree, A., Rodden, T., and Mariani, J. (2004) Collaborating around Collections: Informing the Continued Development of Photoware, Proc ACM CHI'04.

[5] Dourish, P. Where the Action Is: The Foundation of Embodied Interaction. MIT Press. 2001.

[6] Elliot, K., Neustaedter, C. and Greenberg, S. (2005) Time, Ownership and Awareness: The Value of Contextual Locations in the Home. Proc.7th Int'l Conf. on Ubiquitous Computing (Ubicomp'05), LNCS 3660, Springer. 251-268.

[7] Frohlich, D. and Fennell, J. (2007). Sound, paper and memorabilia: resources for a simpler digital photography. Personal Ubiquitous Comput. 11 (2), 107-116

[8] Frohlich, D., Kuchinsky, A., Pering, C., Don, A., Ariss, S. (2002) Requirements for photoware. Proc ACM CSCW '02.

[9] Greenberg, S. and Fitchett, C. (2001) Phidgets: Easy Development of Physical Interfaces through Physical Widgets. Proc ACM UIST'01, 209-218.

[10] Holtzblatt, K, Wendell, J., and Wood, S. 2005. Rapid Contextual Design: A How-To Guide to Key Techniques for User-Centered Design, Morgan Kaufmann.

[11] Jaimes, A., Chang, S. and Loui, A. (2003) Detection of NonIdentical Duplicate Consumer Photographs. Proc ICICSPCM, 16-20.

[12] Kirk, D., Sellen, A., Rother, C., and Wood, K. (2006). Understanding photowork. Proc ACM CHI'06, 761-770.

[13] Miller, A. and Edwards, W.K. (2007) Give and Take: A Study of Consumer Photo-Sharing Culture and Practice. Proc ACM CHI'07, 347-356.

[14] Mugellini, E., Rubegni, E., Gerardi, S., and Khaled, O. (2007) Using Personal Objects as Tangible Interfaces for Memory Recollection and Sharing, Proc TEI'09 1st Intl Conf Tangible and Embedded Interaction, Baton Rouge, USA.

[15] Neustaedter, C., Elliot, K. and Greenberg, S. (2006) Interpersonal Awareness in the Domestic Realm. Proc. OZCHI, 2006.

[16] Norman, D. Emotional Design: Why We Love (or Hate) Everyday Things. Basic Books, 2003.

[17] Rekimoto, J. 1997. Pick-and-Drop: A Direct Manipulation Technique for Multiple Computer Environments. Proc ACM UIST' '97. 31-39.

[18] Rodden, K. and Wood, K. (2003) How do people manage their digital photographs? Proc ACM CHI'03, 409-416.

[19] Shen, C., Lesh, N., Vernier, F., Forlines, C. and Frost, J. (2002) Sharing and building digital group histories. Proc. ACM CSCW'02, 276-290.

[20] Strauss, A., and Corbin, J. 1998. Basics of Qualitative Research: Techniques and Procedures for Developing Grounded Theory, SAGE Publications. 